\title{
Scheduling batches in multi hybrid cell manufacturing system considering worker resources: A case study from pipeline industry
}

\author{
Yilmaz, O.F. ${ }^{a,}{ }^{,}$, Cevikcan, E. ${ }^{a}$, Durmusoglu, M.B. ${ }^{a}$ \\ Industrial Engineering Department, Istanbul Technical University, Maçka/Istanbul, Turkey
}

\section{A B S T R A C T}

This study considers batch scheduling problem in the multi hybrid cell manufacturing system (MHCMS) taking into account worker resources. This problem consists of determining sequence of batches, finding the starting time of each batch, and assigning workers to the batches in accordance with some pre-determined objectives. Due to a lack of studies on the batch scheduling problem in the MHCMS, a binary integer linear goal programming mathematical model is developed for bi-objective batch scheduling problem in this study. The formulated model is difficult to solve for large sized problem instances. To solve the model, we develop an efficient heuristic method called the Hybrid Cells Batch Scheduling (HCBS) heuristic. The proposed HCBS heuristic permits integrating batch scheduling and employee (worker) timetabling. Furthermore, we construct upper and lower bounds for the average flow time and the total number of workers. For evaluation of the performance of the heuristic, computational experiments are performed on generated test instances based on real production data. Results of the experiments show that the suggested heuristic method is capable of solving large sized problem instances in a reasonable amount of CPU time.
\end{abstract}

\section{ARTICLE INFO}

Keywords:

Batch scheduling

Hybrid manufacturing cells

Hybrid cells batch scheduling

Goal programming

Heuristic

HCBS heuristic

*Corresponding author: ofyilmaz@itu.edu.tr omer.faruk.ylmaz89@gmail.com (Yilmaz, O.F.)

Article history:

Received 24 Jun 2016

Revised 14 August 2016

Accepted 24 August 2016

(C) 2016 PEI, University of Maribor. All rights reserved.

\section{References}

[1] Venkataramanaiah, S. (2008). Scheduling in cellular manufacturing systems: an heuristic approach, International Journal of Production Research, Vol. 46, No. 2, 429-449, doi: 10.1080/00207540601138577.

[2] Hachicha, W., Masmoudi, F., Haddar, M., (2007). An improvement of a cellular manufacturing system design using simulation analysis, International Journal of Simulation Modelling, Vol. 6, No. 4, 193-205, doi: 10.2507/IJSIMM06(4)1.089.

[3] Wang, J.X. (2015). Cellular manufacturing: Mitigating risk and uncertainty, CRC Press, Boca Raton, USA, doi: 10.1201/b18009-1.

[4] Wemmerlöv, U., Hyer, N.L. (1989). Cellular manufacturing in the US industry: A survey of users, The international journal of production research, Vol. 27, No. 9, 1511-1530, doi: 10.1080/00207548908942637.

[5] Olorunniwo, F., Udo, G. (2002). The impact of management and employees on cellular manufacturing implementation, International Journal of Production Economics, Vol. 76, No. 1, 27-38, doi: 10.1016/S0925-5273(01)00155-4.

[6] Solimanpur, M., Vrat, P., Shankar, R. (2004). A heuristic to minimize makespan of cell scheduling problem, International journal of production economics, Vol. 88, No. 3, 231-241, doi: 10.1016/S0925-5273(03)00196-8.

[7] Süer, G.A., Tummaluri, R.R. (2008). Multi-period operator assignment considering skills, learning and forgetting in labour-intensive cells, International Journal of Production Research, Vol. 46, No. 2, 469-493, doi: $10.1080 / 00207540601138551$.

[8] Tavakkoli-Moghaddam, R., Javadian, N., Khorrami, A., Gholipour-Kanani, Y. (2010). Design of a scatter search method for a novel multi-criteria group scheduling problem in a cellular manufacturing system, Expert Systems with Applications, Vol. 37, No. 3, 2661-2669, doi: 10.1016/i.eswa.2009.08.012. 
[9] Hyer, H., Wemmerlov, U. (2002). Reorganizing the factory competing through cellular manufacturing, CRC Press, Boca Raton, USA.

[10] Rathinam, B., Govindan, K., Neelakandan, B., Raghavan, S.S. (2015). Rule based heuristic approach for minimizing total flow time in permutation flow shop scheduling, Tehnički vjesnik - Tehnical Gazette, Vol. 22, No. 1, 25-32, doi: 10.17559/TV-20130704132725.

[11] Yang, Z., Qiu, H.-L., Luo, X.-W., Shen, D. (2015). Simulating schedule optimization problem in steel making continuous casting process, International Journal of Simulation Modelling, Vol. 14, No. 4, 710-718, doi: 10.2507/ IISIMM14(4)CO17.

[12] Jensen, J.B. (2000). The impact of resource flexibility and staffing decisions on cellular and departmental shop performance, European Journal of Operational Research, Vol. 127, No. 2, 279-296, doi: 10.1016/S03772217(99)00491-9.

[13] Askin, R.G., Huang, Y. (2001). Forming effective worker teams for cellular manufacturing, International Journal of Production Research, Vol. 39, No. 11, 2431-2451, doi: 10.1080/00207540110040466.

[14] Norman, B.A., Tharmmaphornphilas, W., Needy, K.L., Bidanda, B., Warner, R.C. (2002). Worker assignment in cellular manufacturing considering technical and human skills, International Journal of Production Research, Vol. 40, No. 6, 1479-1492, doi: 10.1080/00207540110118082.

[15] Süer, G.A., Dagli, C. (2005). Intra-cell manpower transfers and cell loading in labor-intensive manufacturing cells, Computers \& Industrial Engineering, Vol. 48, No. 3, 643-655, doi: 10.1016/i.cie.2003.03.006.

[16] Cesaní, V.I., Steudel, H.J. (2005). A study of labor assignment flexibility in cellular manufacturing systems, Computers \& Industrial Engineering, Vol. 48, No. 3, 571-591, doi: 10.1016/i.cie.2003.04.001.

[17] Fowler, J.W., Wirojanagud, P., Gel, E.S. (2008). Heuristics for workforce planning with worker differences, European Journal of Operational Research, Vol. 190, No. 3, 724-740, doi: 10.1016/i.ejor.2007.06.038.

[18] Davis, D.J., Kher, H.V., Wagner, B.J. (2009). Influence of workload imbalances on the need for worker flexibility, Computers \& Industrial Engineering, Vol. 57, No. 1, 319-329, doi: 10.1016/i.cie.2008.11.029.

[19] Fan, J., Cao, M., Feng, D. (2010). Multi-objective dual resource-constrained model for cell formation problem, In: Management of Innovation and Technology (ICMIT), 2010 IEEE International Conference on Management of Innovation and Technology, doi: 10.1109/ icmit.2010.5492881.

[20] Süer, G.A., Alhawari, O. (2012). Operator assignment decisions in a highly dynamic cellular environment, In: Modrák, V., Pandian, R.S. (ed.), Operations management research and cellular manufacturing systems: Innovative methods and approaches, IGI Global, Hershey, PA, USA, 258-276, doi: 10.4018/978-1-61350-047-7.ch012.

[21] Azadeh, A., Sheikhalishahi, M., Koushan, M. (2013). An integrated fuzzy DEA-Fuzzy simulation approach for optimization of operator allocation with learning effects in multi products CMS, Applied Mathematical Modelling, Vol. 37, No. 24, 9922-9933, doi: 10.1016/j.apm.2013.05.039.

[22] Egilmez, G., Erenay, B., Süer, G.A. (2014). Stochastic skill-based manpower allocation in a cellular manufacturing system, Journal of Manufacturing Systems, Vol. 33, No. 4, 578-588, doi: 10.1016/j.jmsy.2014.05.005.

[23] Niakan, F., Baboli, A., Moyaux, T., Botta-Genoulaz, V. (2016). A new multi-objective mathematical model for dynamic cell formation under demand and cost uncertainty considering social criteria, Applied Mathematical Modelling, Vol. 40, No. 4, 2674-2691, doi: 10.1016/j.apm.2015.09.047.

[24] Liu, C., Wang, J., Leung, J.-Y.T. (2016). Worker assignment and production planning with learning and forgetting in manufacturing cells by hybrid bacteria foraging algorithm, Computers \& Industrial Engineering, Vol. 96, 162179, doi: 10.1016/j.cie.2016.03.020.

[25] Das, S.R., Canel, C. (2005). An algorithm for scheduling batches of parts in a multi-cell flexible manufacturing system, International Journal of Production Economics, Vol. 97, No. 3, 247-262, doi: 10.1016/j.ijpe.2004.07.006.

[26] Celano, G., Costa, A., Fichera, S. (2008). Scheduling of unrelated parallel manufacturing cells with limited human resources, International Journal of Production Research, Vol. 46, No. 2, 405-427, doi: 10.1080/002075406011 38452.

[27] Balaji, A.N., Porselvi, S. (2014). Artificial immune system algorithm and simulated annealing algorithm for scheduling batches of parts based on job availability model in a multi-cell flexible manufacturing system, Procedia Engineering, Vol. 97, 1524-1533, doi: 10.1016/j.proeng.2014.12.436.

[28] Jones, D., Tamiz, M. (2010). Practical goal programming, Springer, New York, USA, doi: 10.1007/978-1-4419$\underline{5771-9 .}$.

[29] Dalfard, V.M., Ardakani, A., Banihashemi, T.N. (2011). Hybrid genetic algorithm for assembly flow-shop scheduling problem with sequence-dependent setup and transportation times, Tehnički vjesnik - Tehnical Gazette, Vol. 18, Vol. 4, 497-504.

[30] Nicholas, J., Soni, A. (2005). The portal to lean production: Principles and practices for doing more with less, CRC Press, Boca Raton, USA.

[31] Schaller, J. (2000). A comparison of heuristics for family and job scheduling in a flow-line manufacturing cell, International Journal of Production Research, Vol. 38, No. 22, 287-308, doi: 10.1080/002075400189419. 


\title{
Terminiranje proizvodnih serij v večhibridnem celičnem proizvodnem sistemu $z$ upoštevanjem zaposlenih delavcev: Študija primera iz industrije
}

\author{
Yilmaz, O.F. ${ }^{a,}{ }^{,}$, Cevikcan, E. ${ }^{a}$, Durmusoglu, M.B. ${ }^{a}$ \\ ${ }^{a}$ Industrial Engineering Department, Istanbul Technical University, Maçka/Istanbul, Turkey
}

\section{POVZETEK}

Ta raziskava se ukvarja s problemom terminiranja proizvodnih serij v večhibridnem celičnem proizvodnem sistemu (angl. MHCMS) z upoštevanjem zaposlenih delavcev. Problem se sestoji iz določevanja zaporedja proizvodnih serij, začetka izvajanja vsake serije in določitve delavcev za proizvodnje serije $\mathrm{z}$ ozirom na nekatere predhodno določene cilje. Zaradi pomanjkanja raziskav s področja MHCMS smo v pričujoči raziskavi razvili binarni linearni celoštevilčni matematični model. Razviti model je težko rešljiv, ko je stopnja problema velika. Da bi model uspešno rešili smo razvili učinkovito hevristično metodo, imenovano hibridno hevristično celično terminiranje proizvodnih serij (angl. HCBS). Predlagani pristop HCBS dovoljuje povezavo terminiranja proizvodnih serij in razporeda zaposlenih delavcev. Poleg tega smo zasnovali zgornjo in spodnjo mejo za povprečni pretočni čas in skupno število delavcev. Da bi potrdili zmogljivost predlaganega hevrističnega pristopa smo izvedli več računskih eksperimentov, temelječih na realnih proizvodnih podatkih. Rezultati so pokazali, da je predlagan pristop uspešen pri reševanju problemov z visokimi ravnmi zahtevnosti, in to v razumno kratkem času, ki je potreben za računalniško obdelavo.
\end{abstract}

\section{PODATKI O ČLANKU}

Ključne besede:

Terminiranje proizvodnje Hibridne proizvodne celice

Ciljno programiranje

Hevristika

HCBS hevristika

*Kontaktna oseba: ofyilmaz@itu.edu.tr omer.faruk.ylmaz89@gmail.com (Yilmaz, O.F.)

Zgodovina članka: Prejet 24. junija 2016

Popravljen 14. avgusta 2016 Sprejet 24. avgusta 2016 